\title{
Years of Life Lost due to Diseases of the Digestive System in Poland in 2000-2014
}

\author{
Paulina Paciej-Gołębiowska, Małgorzata Pikala, Irena Maniecka-Bryła
}

Medical University of Łódź, Łódź, Poland
Received: 27.06.2018

Accepted: 10.10 .2018

\begin{abstract}
Background \& Aims: Diseases of the digestive system substantially contribute to premature mortality of the Polish population. Years of Life Lost (YLLs) are more and more commonly used in order to evaluate social and economic aspects of these deaths. The aim of the study was to analyse YLLs due to diseases of the digestive system in Poland between 2000-2014.

Methods: The study material included a database which contained information gathered from 5,601,568 death certificates of Poles who died between 2000-2014. Data on deaths due to diseases of the digestive system were used for the analysis (i.e. coded as K00-K93 according to International Statistical Classification of Diseases and Related Health Problems, 10th Revision). Standard Expected Years of Life Lost (SEYLL) was used to calculate YLLs.

Results: In 2000-2014 diseases of the digestive system contributed to 239,176 deaths of Poles (4.3\% of all deaths), which corresponded to 5,470,096.8 YLLs (95.2 years per 10,000 population). Each death due to the above cause was responsible for the average loss of 22.9 years. Diseases of the liver, including alcoholic liver disease and fibrosis and cirrhosis of the liver, contributed to the highest number of YLLs (54.1\%).

Conclusions: Of all digestive diseases, the dominant causes of YLLs are alcohol-related liver diseases. In order to minimize this phenomenon, it is important to intensify public health activities, aimed at combating alcohol addiction in Poland.
\end{abstract}

Key words: premature mortality - years of life lost - SEYLL - alcohol-related diseases.

Abbreviations: AAPC: average annual percentage changes; APC: annual percentage changes; DALY: Disabilityadjusted Life Years; EU: European Union; GBD: Global Burden of Disease; ICD-10: International Statistical Classification of Diseases and Related Health Problems, 10th Revision; SDR: standardised death rate; SEYLL: Standard Expected Years of Life Lost; YYL: Years of Life Lost; YLD: Years of Life with Disability; WHO: World Health Organisation.

\section{INTRODUCTION}

The main causes of mortality in the Polish population include cardiovascular diseases, malignant neoplasms and external causes of death [1]. These conditions are given particular attention in the professional medical literature [2-4]. Current data indicate that the epidemiological situation in Poland with regards to diseases of the digestive system is also exceptionally negative $[5,6]$. Analyses of the World Health
Organisation (WHO) indicate that standardized death rates due to the above causes are systematically decreasing in Poland; however, they are still higher than mean values noted in European Union (EU) countries. In 2014, the death rate due to diseases of the digestive system in Poland was 30.88 per 100,000 population, whereas the mean value for EU was 26.44 per 100,000 population. The rate of premature mortality due to this reason is particularly alarming - in 2014, its value in the age group 0-64 years was 18.17 per 100,000 Poles, whereas the mean value for the UE was 12.65 per 100,000 population (standardization of rates according to the European population from 1976) [7].

More and more frequently, potential measures, i.e. those which consider living potential of individuals in a population, are applied in epidemiological analyses of premature mortality. They consider not only the number of deaths but also the age 
of a person when the death occurred. A computed number of Years of Life Lost (YLLs) constitutes the basis for the evaluation of social and economic aspects of premature deaths [8-10].

In 2011, diseases of the digestive system were the fifth most important cause of YLLs in the Polish population (5.1 years per 10,000 men and 2.3 years per 10,000 women), and cirrhosis of the liver was the third main cause of YLLs calculated per one death (12.1 years per one male death and 11.3 years per one female death), after road traffic accidents (20.2 years and 17.1 years, respectively) and suicides (17.4 years and 15.4 years, respectively) [11]

The aim of the study was the analysis of YLLs due to diseases of the digestive system in Poland in 2000-2014.

\section{METHODS}

The study material included a database which contained information gathered from 5,601,568 death certificates of inhabitants of Poland who died in the period 2000-2014 (starting with the age of 0 ). The data were provided by the Central Statistical Office in Poland [Suppl. Table 1]. Information on deaths caused by diseases of the digestive system, i.e. bearing codes K00-K93 according to the International Statistical Classification of Diseases and Related Health Problems, 10th Revision (ICD-10), was subject to analysis.

Mortality rates were calculated with the use of data on the size of population obtained from the Local Data Bank of the Central Statistical Office in Poland [1]. Age standardization of rates was performed with a direct method, where the European population updated in 2013 was considered referential [12].

In order to analyze YLLs, the authors used the Standard Expected Years of Life Lost (SEYLL) measure. Its value was calculated according to the original method of Murray and Lopez [9]:

$$
\text { SEYLL }=\sum_{\chi=0}^{\mathrm{I}} \mathrm{d}_{\chi} \mathrm{e}_{\chi}^{*}
$$

where: $\mathrm{e}^{\star} \chi$ stands for a number of expected years of life for a particular age, calculated on the base of referential population; $\mathrm{d} \chi$ stands for a number of deaths at age $\chi ; \chi$ stands for the age at which the person died; 1 is the oldest age in the population.

The authors also used the Standard Expected Years of Life Lost per person (SEYLLp) measure, considering the size of the studied population $(\mathrm{N})$, in this study calculated per 10,000 inhabitants:

$$
S E Y L L_{p}=\frac{\sum_{\chi=0}^{I} d_{\chi} e_{\chi}^{*}}{N}
$$

The Standard Expected Years of Life Lost per death (SEYLLd) measure, which shows the number of years of life lost per one dead person, was calculated by dividing SEYLL due to a particular cause by the number of deaths:

$$
S E Y L L_{d}=\frac{\sum_{\chi=0}^{I} d_{\chi} e_{\chi}^{*}}{\sum_{\chi=0}^{I} d_{\chi}}
$$

In order to compute the above calculations, we implemented a life table prepared by the WHO in 2012. It takes into consideration the mortality rates which are the lowest for each age group in countries with a population higher than 5 million. According to this source, life expectancy of the world's population for both sexes at age 0 is 86.02 years [13].

The time trend analysis was conducted with the application of joinpoint model using the Joinpoint Regression Program. This method is a variant of linear regression analysis in which time trends are expressed in the sequence of segments connected by joinpoints; in these points the changes in values of analyzed parameters are statistically significant $(p<0.05)$. The Permutation test was used to determine the number of joinpoints [14].

Annual percentage changes (APC) in particular time intervals and average annual percentage changes (AAPC) in the whole study period, with their corresponding 95\% confidential intervals $(95 \% \mathrm{CI})$ were calculated for standardized death rate (SDR) and SEYLLp [15].

A brief description of Polish demography is noteworthy in order to better understand the results of the study. Poland is a country with an ageing society characterized by the phenomenon of excess mortality of men compared to women. In 2014, Poland had 38,478,602 inhabitants $(18,619,809$ men and $19,858,793$ women), and among them $15.3 \%$ people were aged 65 years and more (2,273,421 men and 3,600,626 women). Therefore, the female rate in this age group was 1.58 , while for the whole population it was 1.07 [16]. At that time the average life expectancy of a man in Poland was 73.8 years, and of a woman 81.6 years; yet in 2000 it was 69.7 and 78.0 years, respectively [17].

\section{RESULTS}

In 2000-2014, diseases of the digestive system were the cause of 239,176 deaths in the Polish population (4.3\% of all deaths of Poles in the analysed period). Of this number, 136,837 deaths $(57.2 \%)$ occurred in the group of men, and 102,339 deaths $(42.8 \%)$ occurred in the group of women. SDRs due to diseases of the digestive system for the whole population decreased throughout the study period from 5.59 per 10,000 inhabitants in 2000 to 4.67 per 10,000 in 2014. A time trend analysis revealed that the rates were growing by $2.0 \%$ each year in $2000-2005$ ( $\mathrm{p}<0.05,95 \%$ CI: $0.3 ; 3.8)$, but later, they started to decrease by $2.6 \%$ per year and dropped until the end of the analysed period ( $\mathrm{p}<0.05,95 \% \mathrm{CI}:-3.2 ;-1.9)$. AAPC of the SDRs in the whole study period were negative for both sexes. A decrease in the value of the SDR from 7.40 per 10,000 in 2000 to 6.16 per 10,000 in 2014 in males corresponded to an annual decrease of $0.8 \%(\mathrm{p}<0.05,95 \% \mathrm{CI}:-1.7 ;-0.0)$. With regard to females, a downward trend in the rate from 4.17 per 10,000 to 3.43 per 10,000 corresponded to an annual decrease of $1.1 \%$ $(\mathrm{p}<0.05,95 \%$ CI: $-1.8 ;-0.5)$ (Fig. 1, Table I).

Among the diseases of the digestive system, the greatest number of deaths of Poles in 2000-2014 was caused by diseases of the liver - K70-K77 (99,139 deaths - 41.5\%), intestinal diseases K55-K63 (37,252 deaths - 15.6\%) and diseases of the gallbladder, bile ducts and pancreas - K80-K87 (34,983 deaths $-14.6 \%)$. In males, deaths were mostly caused by diseases of the liver $(69,461$ deaths $-50.8 \%)$, gallbladder, bile ducts and pancreas $(18,791-13.7 \%)$ as well as oesophagus, 


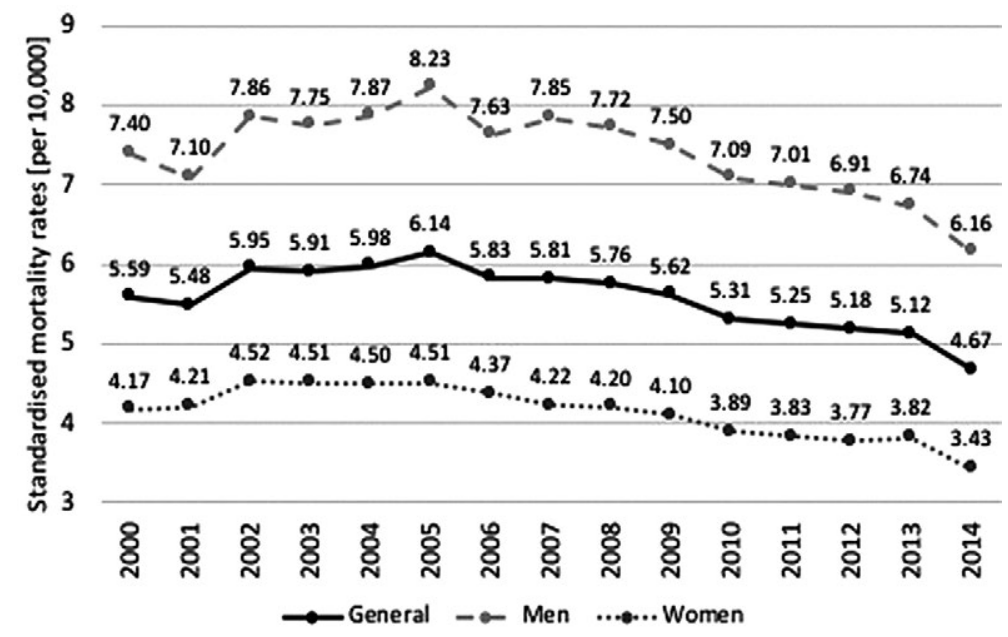

Fig. 1. Standardized death rates due to diseases of the digestive system in Poland in 2000-2014

Table I. Time trends for standardized mortality rates due to diseases of the digestive system in Poland in 2000-2014 by gender per 10,000 population

\begin{tabular}{lccc}
\hline Gender & \multicolumn{2}{c}{ APC [\%] } & \multirow{2}{*}{ AAPC [\%] } \\
\hline \multirow{3}{*}{ all } & $2000-2005$ & $2005-2014$ & \\
\cline { 2 - 3 } males & $2.0^{*}(0.3 ; 3.8)$ & $-2.6^{*}(-3.2 ;-1.9)$ & $-1.0^{*}(-1.6 ;-0.3)$ \\
females & $2.4^{*}(0.3 ; 4.6)$ & $-2.6^{*}(-3.5 ;-1.8)$ & $-0.8^{\star}(-1.7 ;-0.0)$ \\
\hline
\end{tabular}

* changes statistically significant $(\mathrm{p}<0.05)$; AAPC - average annual percentage changes; APC - annual percentage changes.

stomach and duodenum - K20-K31 (15,952 deaths - 11.7\%). Also in females, diseases of the liver contributed to the highest number of deaths $(29,678$ deaths $-29.0 \%)$, next were diseases of intestines (22,781 deaths $-22.3 \%)$ and third, diseases of the gallbladder, bile ducts and pancreas (16,192 deaths - 15.8\%).

In 2000-2014, diseases of the digestive system contributed to a premature loss of 5,470,096.8 years of life (SEYLL) in the Polish population. In males, they contributed to a loss of $3,651,633.8$ years $(66.8 \%)$, whereas in females $1,818,463.0$ years (33.2\%). As calculated per 10,000 people, it was on average 95.2 years (SEYLLp) - 131.4 years in males and 61.7 years in females. Each death due to this cause corresponded to a mean loss of 22.9 years of life (SEYLLd) - 26.7 years in males and 17.8 years in females (Table II).

Between 2000 and 2008, SEYLLp values increased by $2.7 \%$ per year ( $<<0.05,95 \% \mathrm{CI}: 1.4 ; 4.1)$, and decreased in each year on average by $2.5 \%(\mathrm{p}<0.05,95 \% \mathrm{CI}:-4.4 ;-0.5)$. Similar SEYLLp

Table II. Years of life lost due to diseases of the digestive system in Poland in 20002014 by gender

\begin{tabular}{ccccccc}
\hline year & \multicolumn{3}{c}{ males } & & \multicolumn{3}{c}{ females } \\
\hline & SEYLL & SEYLLp & SEYLLd & SEYLL & SEYLLp & SEYLLd \\
\hline 2000 & $231,819.4$ & 125.1 & 27.3 & $112,983.2$ & 57.3 & 18.3 \\
2001 & $218,661.2$ & 118.0 & 26.7 & $114,955.6$ & 58.3 & 18.0 \\
2002 & $221,661.2$ & 119.8 & 26.6 & $111,100.5$ & 56.4 & 17.3 \\
2003 & $219,861.4$ & 118.9 & 26.2 & $112,738.0$ & 57.2 & 17.2 \\
2004 & $238,699.0$ & 129.2 & 26.7 & $118,141.6$ & 60.0 & 17.5 \\
2005 & $256,297.7$ & 138.9 & 26.8 & $122,753.7$ & 62.3 & 17.6 \\
2006 & $252,860.0$ & 137.2 & 27.2 & $126,748.1$ & 64.3 & 18.2 \\
2007 & $265,978.2$ & 144.5 & 27.2 & $131,318.4$ & 66.6 & 18.8 \\
2008 & $275,059.3$ & 149.4 & 27.7 & $134,369.0$ & 68.1 & 18.8 \\
2009 & $260,150.4$ & 141.2 & 26.9 & $129,200.1$ & 65.5 & 18.2 \\
2010 & $247,665.9$ & 132.8 & 26.6 & $121,874.3$ & 61.3 & 17.6 \\
2011 & $249,811.5$ & 133.9 & 26.5 & $123,943.8$ & 62.3 & 17.7 \\
2012 & $249,920.0$ & 134.0 & 26.3 & $125,427.3$ & 63.1 & 17.8 \\
2013 & $239,381.1$ & 128.5 & 25.8 & $127,209.4$ & 64.0 & 17.5 \\
2014 & $223,807.5$ & 120.2 & 25.6 & $115,700.0$ & 58.3 & 17.3 \\
total & $3,651,633.8$ & 131.4 & 26.7 & $1,818,463.0$ & 61.7 & 17.8 \\
\hline
\end{tabular}

SEYLL - Standard Expected Years of Life Lost; SEYLLp - Standard Expected Years of Life Lost per person (per 10,000); SEYLLd - Standard Expected Years of Life Lost per death 
trends were observed for particular sexes. In the initial period, the value for males increased by $2.8 \%$ per year $(p<0.05,95 \%$ CI: $1.5 ; 4.2)$, but in 2008 , it started to decline and decreased by $3.0 \%$ annually until the end of the study period ( $\mathrm{p}<0.05,95 \%$ CI: $-5.0 ;-0.9)$; with regards to females, the value increased by $2.3 \%(\mathrm{p}<0.05,95 \%$ CI: $1.2 ; 3.4)$ and then decreased by $1.7 \%$ per annum ( $\mathrm{p}<0.05,95 \% \mathrm{CI}:-3.4 ;-0.0$ ), respectively (Table IIIA).

Diseases of the liver contributed to the highest number of YLLs. SEYLL due to this cause was 2,960,998.9 years, which corresponded to $54.1 \%$ of all YLLs caused by diseases of the digestive system. In the group of men, it was 2,156,209.1 years $(72.8 \%)$, whereas in the group of women it was $804,789.8$ years $(27.2 \%)$. Calculated per 10,000 population, it was 77.6 years in males and 27.1 years in females. Each death due to this cause contributed to a loss of 31.0 years in males and 27.1 years in females (Table IV).

Of all liver diseases, fibrosis and cirrhosis of the liver - K74, and alcoholic liver disease - K70, contributed to the greatest number of YLLs - 1,555,827.2 years (52.5\%) and 1,154,722.1 years (39.0\%), respectively. Table V presents changes in SEYLLp and SEYLLd values due to selected diseases of the digestive system. Attention is paid to the rapid increase in SEYLLp with a parallel decrease in SEYLLd over time due to alcoholic liver disease. This indicates that the number of deaths due to this cause is growing, but they have shifted to the older age groups.

Average annual percentage changes values of SEYLLP due to fibrosis and cirrhosis of the liver were negative in both sexes. In males, a decline in SEYLLp values from 48.5 years in 2000 to 16.7 years in 2014 corresponded to a decrease of AAPC by $6.3 \%$ yearly $(p<0.05,95 \%$ CI: $-7.9 ;-4.7)$, whereas in females, a decline in the above value from 17.7 years to 9.2 years corresponded to an annual decrease by $3.3 \%(\mathrm{p}<0.05$, 95\% CI: -5.6; -0.9) (Table IIIB). Alcoholic liver disease contributed to increased SEYLLp values in both sexes. In males, it rose from 17.1 years in 2000 to 48.4 years in 2014, which corresponded to an annual increase of $8.9 \%$ ( $\mathrm{p}<0.05$, $95 \%$ CI: $6.0 ; 11.7$ ); and in females, from 3.1 years to 15.1 years, respectively, corresponding to an annual increase by $13.8 \%$ ( $\mathrm{p}<0.05$; 95\%CI: 9.5; 18.3) (Table IIIC).

Table III. Time trends of SEYLLp for diseases of the digestive system in Poland in 2000-2014 by gender: A - in total (K00-K93 according to the ICD-10), B - fibrosis and cirrhosis of the liver (K74), C - alcoholic liver disease (K70), D - acute pancreatitis (K85)

\begin{tabular}{|c|c|c|c|}
\hline \multicolumn{4}{|c|}{ A. } \\
\hline \multirow[t]{2}{*}{ gender } & \multicolumn{2}{|c|}{$\mathrm{APC}[\%]$} & \multirow{2}{*}{ AAPC [\%] } \\
\hline & $2000-2008$ & 2008-2014 & \\
\hline all & $2.7^{\star}(1.4 ; 4.1)$ & $-2.5^{\star}(-4.4 ;-0.5)$ & $0.5(-0.5 ; 1.5)$ \\
\hline males & $2.8^{*}(1.5 ; 4.2)$ & $-3.0^{\star}(-5.0 ;-0.9)$ & $0.3(-0.7 ; 1.3)$ \\
\hline females & $2.3^{*}(1.2 ; 3.4)$ & $-1.7^{\star}(-3.4 ;-0.0)$ & $0.5(-0.3 ; 1.4)$ \\
\hline \multicolumn{4}{|l|}{ B. } \\
\hline \multirow[t]{2}{*}{ gender } & \multicolumn{2}{|c|}{$\mathrm{APC}[\%]$} & \multirow{2}{*}{ AAPC [\%] } \\
\hline & $2000-2009$ & 2009-2014 & \\
\hline all & $0.0(-1.8 ; 1.8)$ & $-14.3^{*}(18.0 ;-10.5)$ & $-5.4^{*}(-7.0 ;-3.7)$ \\
\hline males & $0.4(-2.2 ; 1.3)$ & $-16.0^{*}(19.6 ;-12.3)$ & $-6.3^{*}(-7.9 ;-4.7)$ \\
\hline females & $1.2(-1.3 ; 3.9)$ & $-11.0^{*}(-16.4 ;-5.3)$ & $-3.3^{*}(-5.6 ;-0.9)$ \\
\hline \multicolumn{4}{|l|}{ C. } \\
\hline \multirow[t]{2}{*}{ gender } & \multicolumn{2}{|c|}{ APC [\%] } & \multirow[b]{2}{*}{ AAPC [\%] } \\
\hline & $2000-2008$ & 2008-2014 & \\
\hline all & $14.4^{\star}(10.3 ; 18.6)$ & $3.9(-1.8 ; 0.0)$ & $9.8^{*}(6.7 ; 12.9)$ \\
\hline males & $13.1^{*}(9.4 ; 17.0)$ & $3.3(-1.9 ; 8.9)$ & $8.9^{*}(6.0 ; 11.7)$ \\
\hline females & $20.1^{\star}(14.3 ; 26.3)$ & $5.8(-2.1 ; 14.4)$ & $13.8^{*}(9.5 ; 18.3)$ \\
\hline \multicolumn{4}{|l|}{ D. } \\
\hline \multirow[t]{2}{*}{ gender } & \multicolumn{2}{|c|}{$\mathrm{APC}[\%]$} & \multirow{2}{*}{ AAPC [\%] } \\
\hline & 2000-2009 & 2009-2014 & \\
\hline all & $0.4(-1.1 ; 1.8)$ & $-6.6^{*}(-9.8 ;-3.3)$ & $-2.2^{*}(-3.5 ;-0.8)$ \\
\hline males & $1.3(-0.4 ; 3.0)$ & $-7.1^{*}(-10.8 ;-3.3)$ & $-1.8^{\star}(-3.3 ;-0.3)$ \\
\hline females & & & $-2.9^{*}(-3.7 ;-2.1)$ \\
\hline
\end{tabular}

Table IV. Years of life lost due to diseases of the digestive system in Poland in 2000-2014 by gender and cause

\begin{tabular}{|c|c|c|c|c|c|}
\hline \multirow[t]{2}{*}{ cause } & \multirow[t]{2}{*}{ ICD-10 } & \multicolumn{2}{|c|}{ males } & \multicolumn{2}{|c|}{ females } \\
\hline & & SEYLLp & SEYLLd & SEYLLp & SEYLLd \\
\hline $\begin{array}{l}\text { diseases of the oral cavity, salivary } \\
\text { glands and jaws }\end{array}$ & K00-K14 & 0.0 & 32.2 & 0.0 & 14.8 \\
\hline $\begin{array}{l}\text { diseases of the oesophagus, stomach and } \\
\text { duodenum }\end{array}$ & $\mathrm{K} 20-\mathrm{K} 31$ & 13.0 & 22.6 & 6.4 & 14.4 \\
\hline diseases of the appendix & K35-K38 & 0.3 & 20.3 & 0.2 & 16.2 \\
\hline hernia & K40-K46 & 1.0 & 14.5 & 1.4 & 12.0 \\
\hline non-infective enteritis and colitis & K50-K52 & 1.1 & 23.1 & 1.2 & 17.7 \\
\hline other diseases of intestines & K55-K63 & 9.3 & 17.9 & 9.8 & 12.8 \\
\hline disorders of the peritoneum & K65-K67 & 3.0 & 19.9 & 2.8 & 15.1 \\
\hline diseases of the liver & K70-K77 & 77.6 & 31.0 & 27.1 & 27.1 \\
\hline $\begin{array}{l}\text { diseases of the gallbladder, bile ducts } \\
\text { and pancreas }\end{array}$ & K80-K87 & 18.6 & 27.5 & 8.7 & 15.9 \\
\hline other diseases of the digestive system & K90-K93 & 7.5 & 20.3 & 4.1 & 13.1 \\
\hline total & & 131.4 & 26.7 & 61.7 & 17.8 \\
\hline
\end{tabular}

ICD-10 - International Classification of Diseases and Related Health Problems, 10th Revision; SEYLLp - Standard Expected Years of Life Lost per person (per 10,000); SEYLLd - Standard Expected Years of Life Lost per death. 
Table V. Years of life lost due to selected diseases of the digestive system in Poland in 20002014 by cause

\begin{tabular}{|c|c|c|c|c|c|c|}
\hline \multirow[t]{2}{*}{ year } & \multicolumn{2}{|c|}{ alcoholic liver disease (K70) } & \multicolumn{2}{|c|}{$\begin{array}{l}\text { fibrosis and cirrhosis } \\
\text { of the liver (K74) }\end{array}$} & \multicolumn{2}{|c|}{ acute pancreatitis (K85) } \\
\hline & SEYLLp & SEYLLd & SEYLLp & SEYLLd & SEYLLp & SEYLLd \\
\hline 2000 & 9.9 & 36.3 & 32.6 & 28.5 & 10.7 & 27.0 \\
\hline 2001 & 9.1 & 35.3 & 30.6 & 28.1 & 10.4 & 25.8 \\
\hline 2002 & 10.0 & 35.4 & 29.2 & 28.2 & 10.0 & 25.5 \\
\hline 2003 & 10.7 & 34.4 & 28.3 & 28.3 & 10.0 & 25.0 \\
\hline 2004 & 13.7 & 34.9 & 30.6 & 28.6 & 10.2 & 24.9 \\
\hline 2005 & 15.1 & 34.3 & 32.3 & 28.6 & 10.7 & 25.0 \\
\hline 2006 & 17.8 & 34.4 & 32.3 & 28.9 & 10.1 & 25.8 \\
\hline 2007 & 25.3 & 34.9 & 30.5 & 28.5 & 10.3 & 24.7 \\
\hline 2008 & 26.6 & 33.8 & 31.3 & 28.7 & 11.3 & 25.7 \\
\hline 2009 & 24.2 & 33.2 & 28.7 & 28.1 & 10.6 & 24.8 \\
\hline 2010 & 23.0 & 33.4 & 25.5 & 27.9 & 9.8 & 24.8 \\
\hline 2011 & 25.4 & 33.0 & 23.5 & 27.3 & 9.6 & 25.0 \\
\hline 2012 & 30.0 & 33.1 & 20.4 & 26.4 & 7.8 & 23.4 \\
\hline 2013 & 29.2 & 32.8 & 17.9 & 25.4 & 8.4 & 24.0 \\
\hline 2014 & 31.2 & 31.9 & 12.8 & 24.6 & 7.6 & 23.0 \\
\hline mean & 20.1 & 33.7 & 27.1 & 28.0 & 9.8 & 25.0 \\
\hline
\end{tabular}

SEYLLp - Standard Expected Years of Life Lost per person (per 10,000); SEYLLd - Standard Expected Years of Life Lost per death.

Of all diseases of the digestive system, diseases of the gallbladder, bile ducts and pancreas constituted the second most important cause of YLLs, after liver diseases. They contributed to $773,928.4$ YLLs $(14.2 \%)$ - in males it was $516,715.6$ years $(66.8 \%)$, and in females $257,212.8$ years (33.2\%). This translated into 18.6 years per 10,000 males and 8.7 years per 10,000 females. The SEYLLd value due to this cause was 27.5 years in males and 15.9 years in females. Acute pancreatitis - K85 contributed to the greatest number of YLLs in this group of diseases, i.e. 565,166.2 years (73.0\%). Average annual percentage changes of SEYLLp values due to this cause tended to decrease in both sexes; in males, the value was $-1.8 \%$ $(\mathrm{p}<0.05 ;-3.3 ;-0.3)$, where SEYLLp decreased from 15.0 years in 2000 to 11.1 years in 2014 , and in females, it was $-2.9 \%$ $(\mathrm{p}<0.05 ;-3.7 ;-2.1)$ where SEYLLp decreased from 6.8 years to 4.2 years, respectively (Table IIID).

Besides, the greatest number of YLLs in the class of diseases of the digestive system was caused by diseases of intestines - 549,961.1 years (10.1\%), and diseases of the oesophagus, stomach and duodenum, which contributed to a loss of $549,745.8$ years $(10.1 \%)$.

\section{DISCUSSION}

Diseases of the digestive system are the cause of every 25th death of Poles each year, after cardiovascular diseases, malignant neoplasms, external causes of death and diseases of the respiratory tract [1].

According to Eurostat, in 2014 in the Polish population, SDR due to diseases of the digestive system was 46.9 per 100,000 people (compared to 46.7 per 100,000 stated in our study), which placed Poland the tenth of all $28 \mathrm{EU}$ countries in this respect. With regards to EU countries, the highest values were observed in Slovakia (67.38 per 100,000), whereas the lowest were in Greece $(27.90$ per 100,000) [18].

Among the diseases of the digestive system, in the years 2000-2014, the principal cause in mortality in the Polish population was diseases of the liver comprising alcoholic liver disease as well as fibrosis and cirrhosis of the liver. In each analyzed year, liver diseases contributed to about $40 \%$ of the total number of deaths which occurred in the group of digestive diseases. However, in some European countries, the situation is even worse, i.e. more than every second death which occurs in this group is caused by chronic diseases of the liver. In 2014, the proportional mortality rate due to diseases of the liver was 50.5\% in Slovenia and Hungary, and in Romania it was as high as $62.2 \%$. SDRs due to diseases of the liver were also the highest in the mentioned countries -47.79 per 100,000 population in Romania and 32.36 per 100,000 in Hungary. Poland was the $13^{\text {th }}$ of all EU countries, with the rate of 15.80 per 100,000. The value for Poland exceeded the mean value for the 28 member states, which was 14.30 per 100,000. Among the countries with the SDRs below the European average were Netherlands (4.90 per 100,000), Greece (6.64 per 100,000), Italy $(8.81$ per 10,000$)$ and France $(10.88$ per 10,000$)$ [19].

Alcohol consumption undoubtedly affects the geographical distribution of the mortality rate due to the above causes. It was confirmed that it was not only the amount of consumed alcohol (including unregistered home-made alcoholic beverages) but also the type of alcohol and the drinking pattern that mattered $[20,21]$. The WHO data indicates that over the period 20002014, consumption of pure alcohol in Poland increased from 8.40 to 10.71 litres per person, and since 2008 , its value has been continually higher than the mean value for $\mathrm{EU}$ countries. 
This observation appears to be alarming when we consider the fact that the average alcohol consumption in EU countries tended to decrease at that time - it declined from 11.14 litres per person in 2000 to 10.17 litres in 2014. Another worrying aspect concerns the type of alcohol consumed by Poles; a high consumption of spirits and beer continues to rise, whereas consumption of wine is decreasing [7].

It is difficult to compare the epidemiological situation between particular countries with regards to the YLLs caused by diseases of the digestive system (as well as other diseases), due to the different methodology used for calculation purposes. The authors of this study used the SEYLL index in order to determine premature mortality, and a life table published by the WHO was used to make calculations [13]. However, other measures are also in use in medical literature, including Potential Years of Life Lost (PYLL) or Period Expected Years of Life Lost (PEYLL). Besides, other referential values can be used to calculate SEYLL, e.g. the Coale-Demeny's life tables prepared on the basis of the Japanese population $[5,11,22]$.

The Global Burden of Disease (GBD) study systematically undertakes estimates of YLLs for various populations and according to different causes. The analyses show that in the year 2014, Poland was the 11th of all EU countries with regards to YLLs caused by cirrhosis and other chronic liver diseases due to alcohol use. With regards to mortality rates due to this disease, Poland was the 17th [23]. This divergence indicates that the phenomenon of premature mortality due to diseases of the liver, particularly those related to alcohol consumption, is an important problem in the Polish population. This assumption was confirmed by our study, which revealed that throughout the whole analyzed period in the group of diseases of the digestive system, the percentage of YLLs due to diseases of the liver was higher than the percentage of deaths.

Furthermore, analyses of the GBD Study indicate that, in 2014, the value of the Disability-Adjusted Life Years (DALY) measure due to cirrhosis and other chronic liver diseases caused by alcohol abuse, which comprises YLLs and Years of Life with Disability (YLDs), placed Poland the 13th of all EU countries. The highest values of DALY due to the above diseases were observed in Romania and Hungary, while the lowest values were noted in Italy and Netherlands [23]. The analyses also included the relationship between selected risk factors for chronic diseases and the DALY value in particular populations. With regards to this, alcohol consumption was the sixth most important risk factor in the Polish population in 2015. A similar observation was made for whole Central Europe, but in Eastern Europe this risk factor occupied the third position. Globally, it is on the ninth position [24].

Alcohol-related premature mortality is therefore a major problem in European countries [25]. Rehm et al. [21] confirmed that in 2002, in eight European countries almost $15 \%$ of deaths $(17.3 \%$ in males and $8.0 \%$ in females) aged 20-64 years, were caused by excessive alcohol consumption. Another study, conducted in the years 2006-2012 in Mexico City, revealed that alcohol-related mortality rates were $3.9 \%$ in males and $0.4 \%$ in females [26]. In Canada, $7.7 \%$ of deaths in people aged 0-64 years, which occurred in 2005, were caused by alcohol abuse [27]. A study conducted in San Francisco in 2004-2007 revealed that about 10\% of YLLs in males and about $5 \%$ in females were related to excessive alcohol use [28]. All the mentioned studies noted that male mortality was distinctively higher than that of females due to this cause, which corresponded to the results obtained by us.

Combating alcohol abuse is still one of the most crucial tasks for organisations and bodies dealing with public health problems in Poland. It is estimated that each year expenditure of the Polish budget due to alcohol-related problems constitutes $1.3 \%$ of the Gross Domestic Product [29]. Minimizing this negative trend is one of the objectives of the National Health Programme for the years 2016-2020 [30]. Similar initiatives are implemented at the European level as well as all around the world. Since 2010, 193 WHO member states, in their attempts to reduce alcohol abuse, have been following the Global Strategy to Reduce Harmful Use of Alcohol [31]. The attempts to identify people abusing alcohol and to implement appropriate health education, as part of preventive programs conducted in local communities seem to be recommended. A positive example of such activities is the cardiovascular preventive program run in Poland [32]. Efforts aimed at reducing cardiovascular risk of Polish residents could also have an impact on improving health in the field of digestive system diseases. This may be reflected by the gradual decline in the values of SEYLLp due to this cause observed since 2008, after a previous upward trend.

These positive changes in the whole group of diseases of the digestive system were related to the decrease in SEYLLp values due to fibrosis and cirrhosis of the liver and acute pancreatitis. However, SEYLLp due to alcoholic liver disease showed an upward trend throughout the study period. An improvement in the SEYLLd values due to alcoholic liver disease, which indicates the shift of these deaths to older age groups, gives the hope for a forthcoming gradual reduction of the phenomenon of premature mortality due to this reason.

\section{CONCLUSIONS}

Application of potential measures is crucial in the evaluation of an epidemiological situation associated with premature mortality. This analysis revealed that in the 15 -year study period, diseases of the digestive system contributed to 136,837 deaths (57.2\%) in males and 102,339 deaths (42.8\%) in females, which corresponded to a loss of $3,651,633.8$ YLLs (66.8\%) in males and $1,818,463.0$ years $(33.2 \%)$ in females. SEYLLp values due to this cause were 131.4 and 61.3 years, respectively, whereas SEYLLd values were 26.7 and 17.8 years. Diseases of the liver were the greatest factor causing potential loss of life (2.960.998.9 YLLs - 54.1\%), which contributed to a loss of 77.6 years per 10,000 males and 27.1 years per 10,000 females. In this group, the dominant role was occupied by fibrosis and cirrhosis of the liver $(1,555,827.2$ years $-52.5 \%)$ and alcoholic liver disease $(1,154,722.1$ years $-39.0 \%)$. In order to minimize this phenomenon, it is important to intensify public health activities, aimed at combating alcohol addiction in Poland.

Conflicts of interest: No conflict to declare.

Authors' contributions: P.P.G.: statistical analysis, data interpretation, literature search, manuscript preparation; M.K: study design, data 
collection, funds collection; I.M.B: study design, literature search, funds collection.

Acknowledgement: The study was financed by the Medical University of Łódź from the grant number 503/6-029-07/503-61-001.

Supplementary material: To access the supplementary material visit the online version of the J Gastrointestin Liver Dis at http://www. jgld.ro/wp/archive/y2018/n4/a12 and http://dx.doi.org/10.15403/ jgld.2014.1121.274.yrs

\section{REFERENCES}

1. Central Statistical Office in Poland. Local Data Bank. Cited 10 Nov 2017. Available from: http://www.bdl.stat.gov.pl

2. Maniecka-Bryla I, Pikala M, Bryla M. Life years lost due to cardiovascular diseases. Kardiol Pol 2013;71:1065-1072. doi:10.5603/ KP.2013.0262

3. Pikala M, Maniecka-Bryła I. Years of life lost due to malignant neoplasms characterized by the highest mortality rate. Arch Med Sci 2014;10:9991006. doi:10.5114/aoms.2013.36237

4. Pikala M, Bryła M, Bryła P, Maniecka-Bryla I. Years of life lost due to external causes of death in the Lodz province, Poland. PLoS One 2014;9:e96830. doi:10.1371/journal.pone.0096830

5. Paciej P, Ciabiada B, Maniecka-Bryła I. Lost Life Years Due to premature deaths caused by diseases of the digestive system in Poland in 2013 Przegl Epidemiol 2016;70:500-507.

6. Paciej P, Ciabiada B, Maniecka-Bryła I. Premature mortality due to alcohol-related diseases of the liver in Poland according to voivodships. Fam Med Prim Care Rev 2017;19:251-255. doi:10.5114/ fmpcr.2017.69287

7. World Health Organization Regional Office for Europe. European health for all database. Cited 10 Nov 2017. Available from: http://data.euro. who.int/hfadb/

8. Marshall RJ. Standard Expected Years of Life Lost as a measure of disease burden: An investigation of its presentation, meaning and interpretation. In: Preedy VR, Watson RR, eds. Handbook of disease burdens and quality of life measures. Berlin: Springer; 2009:3421 3434.

9. Murray CJL, Lopez AD. The Global Burden of Disease. A comprehensive assessment of mortality and disability from diseases, injuries and risk factors in 1990 and projected to 2010. Boston: Harvard University Press; 1996.

10. Pikala M, Maniecka-Bryła I. Fifteen-year mortality trends in Poland analysed with the use of standard expected years of life lost, 2000 2014. Sci Rep 2017;7:8730. doi:10.1038/s41598-017-09441-5

11. Maniecka-Bryła I, Bryła M, Bryła P, Pikala M. The burden of premature mortality in Poland analysed with the use of standard expected years of life lost. BMC Public Health 2015;15:101. doi:10.1186/s12889-015-1487-x

12. Eurostat. Revision of the European Standard Population Report of Eurostat's task force - 2013 edition. Luxembourg: Publications Office of the European Union; 2013. doi:10.2785/11470

13. Murray CJ, Ezzati M, Flaxman AD, et al. GBD 2010: design, definitions and metrics. Lancet 2012;380:2063-2066. doi:10.1016/S01406736(12)61899-6

14. Joinpoint Regression Program, Version 4.2.0-April 2015; Statistical Methodology and Applications Branch, Surveillance Research Program, National Cancer Institute.
15. Estimated APC. Surveillance Research Program, National Cancer Institute. Cited 01 Dec 2017. Available from: https://surveillance. cancer.gov/search?q=APC\&collection $=$ srp\&frontend $\% 20=\operatorname{srp} \& b \operatorname{tn} G$ $\mathrm{x}=0$ \&btnG. $\mathrm{y}=0$

16. Central Statistical Office in Poland. Demographic Yearbook of Poland 2015. Cited 11 Sept 2018. Available from: https://stat.gov.pl/obszarytematyczne/roczniki-statystyczne/roczniki-statystyczne/rocznikdemograficzny-2015,3,9.html

17. Central Statistical Office in Poland. Life Expectancy Tables of Poland 2016. Cited 11 Sept 2018. Available from: https://stat.gov.pl/obszarytematyczne/ludnosc/trwanie-zycia/trwanie-zycia-tablice,1,1.html

18. Eurostat statistics. Cited 13 Dec 2017. Available from: http://ec.europa eu/eurostat/web/health/causes-death/data/database

19. World Health Organisation. Mortality Database. Cited 13 Dec 2017 Available from: http://apps.who.int/healthinfo/statistics/mortality/ whodpms/

20. Rehm J, Room R, Monteiro M, et al. Alcohol as a risk factor for global burden of disease. Eur Addict Res 2003;9:157-164. doi:10.1159/000072222

21. Rehm J, Sulkowska U, Mańczuk M, et al. Alcohol accounts for a high proportion of premature mortality in central and eastern Europe. Int J Epidemiol 2007;36:458- 467. doi:10.1093/ije/dyl294

22. Murray CJ, Ahmad OB, Lopez AD, et al. WHO System of Model Life Tables. Cited 13 Dec 2017. Available from: http://www.who.int/ healthinfo/paper08.pdf

23. Global Burden of Diseases. GBD Results Tool. Cited 08 Jan 2018. Available from: http://ghdx.healthdata.org/gbd-results-tool

24. GBD 2015 Risk Factors Collaborators. Global, regional and national comparative risk assessment of 79 behavioral, environmental and occupational, and metabolic risks or cluster of risks, 1990-2015: a systematic analysis for the Global Burden of Disease Study 2015. Lancet 2016;388:1659-1724. doi:10.1016/S0140-6736(16)31679-8

25. World Health Organisation. Global status report on alcohol and health 2014.Cited 13 Dec 2017. Available from: http://www.who.int/substance abuse/publications/global_alcohol_report/msb_gsr_2014_1.pdf

26. Pérez-Pérez E, Cruz-López L, Hernández-Llanes NF, et al. Years of life lost (Yll) attributable to alcohol consumption in Mexico City. Cien Saude Colet 2016;21:37-44. doi:10.1590/1413-81232015211.09472015

27. Shield KD, Taylor B, Kehoe T, Patra J, Rehm J. Mortality and potential years of life lost attributable to alcohol consumption in Canada in 2005 BMC Public Health 2012;12:91. doi:10.1186/1471-2458-12-91

28. Katcher BS, Reiter RB, Aragón TJ. Estimating alcohol-related premature mortality in San Francisco: use of population-attributable fractions from the Global Burden of Disease Study. BMC Public Health 2010;10:682. doi:10.1186/1471-2458-10-68

29. Anderson P, Baumberg B. Alcohol in Europe - Public health perspective Report summary. Drugs: Education, Prevention and Policy 2006;13:483488. doi:10.1080/09687630600902477

30. Polish Ministry of Health. National Health Program for 2016-2020. Cited 08 Mar 2018. Available from: https://www.gov.pl/zdrowie/ narodowy-program-zdrowia-na-lata-2016-2020

31. World Health Organization. Global strategy to reduce the harmful use of alcohol 2010. Cited 08 Mar 2018. Available from: http://www.who. int/substance_abuse/activities/globalstrategy/en/index.html

32. Maniecka-Bryła I, Maciak-Andrzejewska A, Bryła M, Bojar I. An assessment of health effects of a cardiological prophylaxis programme in a local community with the use of the SCORE algorithm. Ann Agric Environ Med 2013;20:794-799. 
Supplementary Table I. Causes of death in Poland 2000-2014

\begin{tabular}{|c|c|c|c|c|c|c|c|c|c|}
\hline group of diseases & ICD-10 groups & 2000 & 2001 & 2002 & 2003 & 2004 & 2005 & 2006 & 2007 \\
\hline infectious and parasitic diseases & $\mathrm{A}, \mathrm{B}$ & 866 & 837 & 872 & 816 & 782 & 827 & 886 & 855 \\
\hline neoplasms & $\mathrm{C}$ & 36537 & 37208 & 37459 & 38328 & 38510 & 39345 & 39855 & 40610 \\
\hline diseases of the blood and blood-forming organs & $\mathrm{D}$ & 1154 & 1183 & 1285 & 1431 & 1288 & 1294 & 1337 & 1639 \\
\hline endocrine, nutritional and metabolic diseases & $\mathrm{E}$ & 3458 & 3396 & 3400 & 3395 & 3364 & 3408 & 3774 & 3825 \\
\hline mental and behavioural disorders & $\mathrm{F}$ & 246 & 262 & 254 & 314 & 291 & 295 & 265 & 325 \\
\hline diseases of the nervous system & G & 1788 & 1911 & 1994 & 1955 & 2155 & 2454 & 2468 & 2562 \\
\hline diseases of the eye and adnexa, ear and mastoid process & $\mathrm{H}$ & 2 & 1 & 3 & 0 & 2 & 2 & 0 & 1 \\
\hline diseases of the circulatory system & I & 91729 & 91117 & 89163 & 90934 & 88750 & 88972 & 88824 & 90589 \\
\hline diseases of the respiratory system & $\mathrm{J}$ & 7819 & 6474 & 6195 & 7145 & 6697 & 7481 & 7341 & 7644 \\
\hline diseases of the digestive system & $\mathrm{K}$ & 6176 & 6375 & 6428 & 6536 & 6733 & 6968 & 6979 & 6975 \\
\hline diseases of the skin and subcutaneous tissue & $\mathrm{L}$ & 32 & 22 & 23 & 15 & 19 & 16 & 24 & 19 \\
\hline diseases of the musculoskeletal system and connective tissue & M & 446 & 426 & 396 & 450 & 456 & 419 & 390 & 370 \\
\hline diseases of the genitourinary system & $\mathrm{N}$ & 2028 & 1961 & 1997 & 1946 & 2090 & 2288 & 2436 & 2331 \\
\hline pregnancy, childbirth and the puerperium, certain conditions originated in perinatal period & $\mathrm{O}, \mathrm{P}$ & 628 & 601 & 598 & 568 & 539 & 500 & 540 & 537 \\
\hline congenital malformations, deformations and chromoson=mal abnormalities & Q & 695 & 629 & 562 & 527 & 501 & 530 & 442 & 477 \\
\hline external causes of morbidity, injury, poisoning and certain other consequences of external causes & $S, T, V, W, X, Y$ & 6731 & 6441 & 6499 & 6119 & 6018 & 6152 & 6072 & 5824 \\
\hline other causes of death & $\mathrm{R}, \mathrm{Z}, \mathrm{U}$ & 12303 & 11515 & 10703 & 10841 & 10640 & 10548 & 9755 & 10408 \\
\hline total & & 172638 & 170359 & 167831 & 171320 & 168835 & 171499 & 171388 & 174991 \\
\hline
\end{tabular}




\section{Supplementary Table I. Continued}

\begin{tabular}{|c|c|c|c|c|c|c|c|c|}
\hline group of diseases & ICD-10 groups & 2008 & 2009 & 2010 & 2011 & 2012 & 2013 & 2014 \\
\hline infectious and parasitic diseases & $\mathrm{A}, \mathrm{B}$ & 1057 & 1129 & 1129 & 1317 & 1144 & 813 & 821 \\
\hline neoplasms & $\mathrm{C}$ & 40841 & 40895 & 40793 & 40644 & 42041 & 41919 & 42875 \\
\hline diseases of the blood and blood-forming organs & $\mathrm{D}$ & 1377 & 1647 & 1820 & 1992 & 2065 & 2465 & 2310 \\
\hline endocrine, nutritional and metabolic diseases & $\mathrm{E}$ & 4084 & 4121 & 3971 & 4167 & 4333 & 4440 & 4056 \\
\hline mental and behavioural disorders & $\mathrm{F}$ & 332 & 283 & 296 & 302 & 301 & 328 & 314 \\
\hline diseases of the nervous system & G & 2541 & 2786 & 2777 & 2955 & 3154 & 3188 & 2851 \\
\hline diseases of the eye and adnexa, ear and mastoid process & $\mathrm{H}$ & 1 & 0 & 0 & 0 & 1 & 0 & 1 \\
\hline diseases of the circulatory system & I & 91415 & 94352 & 92519 & 90526 & 94397 & 94910 & 90917 \\
\hline diseases of the respiratory system & $\mathrm{J}$ & 7728 & 8446 & 7846 & 8108 & 8433 & 9841 & 8760 \\
\hline diseases of the digestive system & K & 7132 & 7114 & 6912 & 7010 & 7064 & 7268 & 6669 \\
\hline diseases of the skin and subcutaneous tissue & $\mathrm{L}$ & 16 & 20 & 28 & 50 & 81 & 102 & 117 \\
\hline diseases of the musculoskeletal system and connective tissue & M & 387 & 375 & 350 & 407 & 423 & 454 & 431 \\
\hline diseases of the genitourinary system & $\mathrm{N}$ & 2443 & 2614 & 2688 & 2665 & 2629 & 2278 & 1516 \\
\hline pregnancy, childbirth and the puerperium, certain conditions originated in perinatal period & $\mathrm{O}, \mathrm{P}$ & 567 & 563 & 482 & 401 & 393 & 385 & 356 \\
\hline congenital malformations, deformations and chromoson=mal abnormalities & Q & 466 & 481 & 435 & 443 & 467 & 424 & 432 \\
\hline external causes of morbidity, injury, poisoning and certain other consequences of external causes & $\mathrm{S}, \mathrm{T}, \mathrm{V}, \mathrm{W}, \mathrm{X}, \mathrm{Y}$ & 6018 & 5658 & 5397 & 5427 & 5576 & 5434 & 5201 \\
\hline other causes of death & $\mathrm{R}, \mathrm{Z}, \mathrm{U}$ & 10653 & 10630 & 11202 & 10909 & 10192 & 11367 & 13049 \\
\hline total & & 177058 & 181114 & 178645 & 177323 & 182694 & 185616 & 180676 \\
\hline
\end{tabular}

